\title{
PEMANFAATAN MEDIA SOSIAL TIK TOK SEBAGAI SARANA PENGUATAN IDENTITAS NASIONAL DI ERA PANDEMI
}

\author{
Muhammad Wahyu Nugroho ${ }^{1}$, Supriyono ${ }^{2}$, Dadi Mulyadi Nugraha ${ }^{3}$ \\ ${ }^{1}$ Departemen Pendidikan Bahasa dan Sastra Indonesia, Universitas Pendidikan Indonesia \\ ${ }^{2,3}$ Departemen Pendidikan Umum, Universitas Pendidikan Indonesia \\ Jl. Dr. Setiabudi No.229, Isola, Sukasari, Kota Bandung 40154 \\ ${ }^{1}$ Email: muhammadwahyu@upi.edu \\ ${ }^{2}$ Email: supriyono@upi.edu \\ ${ }^{3}$ Email: dadimulyadi301190@upi.edu
}

\begin{abstract}
ABSTRAK
Media sosial merupakan salah satu solusi agar tetap bisa berkomunikasi dan mendapatkan informasi di era pandemi. Salah satu jenis media sosial yang digunakan adalah Tik Tok. Penelitian yang dilaksanakan bertujuan untuk mengetahui bagaimana pemanfaatan media sosial Tik Tok sebagai sarana penguatan identitas nasional di era pandemi. Penelitian ini menggunakan metode deskriptif kualitatif dengan populasi video Tik Tok. Pengumpulan data dilakukan dengam teknik pengamatan, pendokumentasian, dan juga pencatatan. Dari hasil data tersebut dilakukan analisis kepada setiap video yang bisa memberikan penguatan kepada pengguna aplikasi Tik Tok mengenai identitas nasional. Hasil dari penelitian tersebut menunjukkan adanya penguatan identitas nasional pada media sosial Tik Tok, seperti diantaranya dalam bentuk bahasa Indonesia sebagai bahasa nasional, Bendera Merah Putih sebagai bendera negara, Lagu Indonesia raya sebagai lagu kebangsaan, Garuda Pancasila sebagai lambang negara, Bhineka Tunggal Ika sebagai semboyan negara, Pancasila sebagai dasar negara, dan kebudayaan daerah yang telah diterima sebagai kebudayaan nasional.
\end{abstract}

Kata Kunci: Identitas, Nasional, Tik tok, Pandemi

\begin{abstract}
Social media is one of many solutions in order to communicate with others and get informations in the era of a pandemic. One type of social media that people often used is Tik Tok. This research's aim is to see the use of social media especially Tik Tok as a medium to strengthen the national identity in the pandemic era. This research uses qualitative descriptive method with the Tik Tok video population as the data. Data was collected using observation, documentation, and recording techniques. From the results of that, an analysis is carried out on each video that can provide reinforcement to Tik Tok application users regarding national identity. The results of this study indicate the strengthening of national identity in Tik Tok social media, such as identity of Indonesian as the national language, the Red and White Flag as the national flag, the Indonesian song Raya as the national anthem, Garuda Pancasila as the national symbol, Bhineka Tunggal Ika as the country's motto, Pancasila as the basis of the state, and regional culture that have been accepted as national culture.
\end{abstract}

Keyword: Identity, Nasional, Tik tok, Pandemic 


\section{PENDAHULUAN}

Identitas nasional adalah pemahaman tentang negara yang menyangkut penciptaan identitas nasional itu sendiri dan sudah menjadi aturan yang telah mendapatkan kesepakatan bersama (Astawa, 2017). Identitas nasional sangat penting bagi bangsa Indonesia. Identitas nasional suatu bangsa, khususnya bagi bangsa Indonesia akan ditentukan oleh ideologi yang diadopsi dan prinsip-prinsip dasar negara sebagai kode etik yang berlaku. Identitas tersebut akan menjadi ciri khas yang membedakan bangsa Indonesia dengan bangsa lain. Identitas bangsa dapat diidentifikasikan dari sifat eksternal yang dapat terlihat dan sifat internal yang hanya dapat dirasakan oleh hati nurani (PKN, 2021).

Identitas nasional merupakan salah satu hal yang dikaji dalam Pendidikan Kewarganegaraan. Pendidikan Kewarganegaraan bertujuan untuk mewujudkan warga negara yang mempunyai daya saing, bersikap disiplin, dan dapat aktif turut serta dalam menjalani kehidupan yang damai berdasarkan sistem pancasila (Budiutomo, 2013). Identitas nasional juga dapat menumbuhkan rasa cinta tanah air. Dalam pandangan pendidikan karakter, cinta tanah air berarti metode berpikir, berperan, serta berwawasan yang menempatkan kepentingan bangsa serta bernegara di atas kepentingan diri serta kelompoknya (Wael, A., Tiggapy, 2021).

Di era pandemi covid 19, penguatan identitas nasional seperti kegiatan pembelajaran Pendidikan Kewarganegaraan, upacara bendera, serta kegiatan budaya menjadi sulit dilaksanakan secara luring. Padahal, kegiatan yang berkaitan dengan pendidikan kewarganegaraan dan juga kebudayaan nasional dapat meningkatkan rasa jati diri bangsa. Hal tersebut menumbuhkan kebanggaan, sikap nasionalisme dan patriotisme terhadap bangsa dan negara.

Sulitnya berkegiatan di luar ruangan, berkaitan dengan protokol kesehatan yang harus diterapkan oleh seluruh masyarakat. Hal tersebut menyebabkan masyarakat harus mencari media alternatif lain agar tetap bisa melaksanakan kegiatannya baik belajar atau bekerja. Dalam hal ini, media sosial menjadi salah satu pilihannya. Media sosial merupakan media daring yang dapat membuat para penggunanya bisa dengan gampang berpartisipasi, berbagi, serta membuat konten, tercantum web, jejaring sosial, Wiki, forum, serta dunia maya (Cahyono, 2016). Media sosial memiliki kekuatan untuk memengaruhi banyak masyarakat Indonesia pada waktu yang singkat. Pengaruh media sosial sangat jelas terlihat pada jumlah masyarakat pengguna media sosial saat ini. Hal ini menyebabkan 
media sosial dapat mempengaruhi perilaku pribadi dan nilai-nilai masyarakat yang menunjang lingkungan serta Individu seseorang (Bayu et al., 2020).

Media sosial yang marak dipakai masyarakat pada masa pandemi ini salah satunya adalah Tik Tok. Aplikasi Tik Tok merupakan salah satu platform yang menawarkan fitur video singkat dan musik. Aplikasi Tik Tok berasal dari Tiongkok dan secara resmi diluncurkan pada bulan September 2016. Aplikasi ini memungkinkan pengguna membuat video musik pendek mereka sendiri (Aji, 2018). Menurut CNBC Indonesia, pada 25 Agustus 2020, berdasarkan laporan Tik Tok, jumlah pengguna Tik Tok aktif hingga Juli 2020 mencapai 689,17 juta pengguna di dunia. Menurut Rahadian (2020) untuk sebuah aplikasi yang baru memiliki usia 4 tahun, ini adalah sebuah pencapaian yang luar biasa.

Aplikasi Tik Tok pernah menjadi persoalan yang pro dan kontra di masyarakat. Bahkan, aplikasi tersebut pernah di blokir di Indonesia. Pada Selasa, 3 Juli 2018, Kominfo mengumumkan secara resmi pemblokiran Tik Tok. Kominfo memblokir delapan nama domain atau DNS yang terkait dengan Tik Tok ("Kominfo: Blokir Tik Tok Hanya Sementara," 2018). Namun, hal tersebut tidak bertahan lama dan aplikasi Tik Tok kembali bisa diakses oleh masyarakat. terdapat lebih dari 10 juta orang di Indonesia yang sebagian besar adalah anak usia sekolah (pelajar), sehingga terlihat bahwa aplikasi Tik Tok merupakan aplikasi yang disukai dan diminati oleh generasi milenial yang sebagian besar adalah anak usia sekolah (Aji, 2018). Hal ini harus disikapi secara baik oleh masyarakat, aplikasi Tik Tok harus digunakan untuk keperluan yang bermanfaat, seperti kebutuhan edukasi dan pembelajaran sehingga stigma negatif yang ada di aplikasi ini dapat terbantahkan.

Dari hal tersebut, fitur yang terdapat di aplikasi Tik Tok dapat mendukung berbagai kegiatan yang berkaitan dengan penguatan identitas nasional, baik mengenai bentuk dan juga contoh-contoh pengaplikasiannya yang dapat dilaksanakan pada era pandemi. Fitur yang disediakan pun dikemas secara menarik dan simpel karena konten yang ditampilkan di aplikasi Tik Tok berupa video pendek.

Berdasarkan premis yang sudah dipaparkan, aplikasi Tik Tok memenuhi kriteria sebagai media penguatan terhadap identitas nasional. hal tersebut diihat dari jumlah penggunanya dan juga fitur yang bisa digunakan. halmasa pandemi covid 19 yang menyebabkan segala sesuatu dilaksanakan secara daring. 


\section{METODE PENELITIAN}

Penelitian ini menggunakan metode deskriptif kualitatif. Metode deskriptif kualitatif adalah suatu teknik yang mendeskripsikan dan menafsirkan makna dari data yang dikumpulkan dengan memperhatikan dan mencatat banyak aspek dari situasi yang diteliti pada saat itu, sehingga diperoleh pemahaman yang menyeluruh tentang situasi yang sebenarnya (Kriyantono, 2007). Populasi dalam penilitian ini adalah video yang ada di aplikasi Tik Tok. Pengumpulan data dilakukan dengam teknik pengamatan, pendokumentasian, dan pencatatan. Dari hasil data tersebut dilakukan analisis kepada setiap video yang bisa memberikan penguatan kepada pengguna aplikasi Tik Tok mengenai identitas nasional.

\section{HASIL DAN PEMBAHASAN}

Dari hasil penelitian dan pengamatan, ditemukan tagar ataupun video dari aplikasi Tik Tok yang merepresentasikan beberapa bentuk identitas nasional.

\begin{tabular}{|c|c|c|c|}
\hline $\mathrm{NO}$ & $\begin{array}{c}\text { Bentuk Identitas } \\
\text { Nasional }\end{array}$ & $\begin{array}{c}\text { Nama Tagar atau Akun } \\
\text { Tik Tok }\end{array}$ & $\begin{array}{c}\text { Deskripsi Singkat Isi Tagar } \\
\text { atau Video }\end{array}$ \\
\hline 1 & $\begin{array}{l}\text { Bahasa Indonesia } \\
\text { sebagai bahasa } \\
\text { nasional }\end{array}$ & $\begin{array}{l}\text { 1. @Narasi } \\
\text { 2. @ tanyabueidya }\end{array}$ & $\begin{array}{l}\text { 1. Hal yang perlu kamu } \\
\text { kamu tahu tentang Bahasa } \\
\text { Indonesia dan Sumpah } \\
\text { Pemuda } \\
\text { 2. } 7 \text { Negara di dunia yang } \\
\text { mempelajari bahasa } \\
\text { Indonesia }\end{array}$ \\
\hline 2 & $\begin{array}{l}\text { Bendera merah putih } \\
\text { sebagai bendera } \\
\text { negara }\end{array}$ & $\begin{array}{l}\text { 1. @ teriyuloh } \\
\text { 2. @ tiktokwillykun }\end{array}$ & $\begin{array}{l}\text { 1. } 3 \text { fakta menarik bendera } \\
\text { merah putih } \\
\text { 2. Arti bendera merah putih }\end{array}$ \\
\hline 3 & $\begin{array}{l}\text { Lagu Indonesia Raya } \\
\text { sebagai lagu } \\
\text { kebangsaan }\end{array}$ & $\begin{array}{l}\text { 1. @ } @ \text { hai_online } \\
\text { 2. @ fahrul khakim }\end{array}$ & $\begin{array}{l}\text { 1. Throwback ketika NIKI } \\
\text { nyanyikan Indonesia Raya } \\
\text { di Los Angeles } \\
\text { 2. Fakta lagu Indonesia Raya }\end{array}$ \\
\hline 4 & $\begin{array}{l}\text { Garuda Pancasila } \\
\text { sebagai lambang } \\
\text { negara }\end{array}$ & $\begin{array}{l}\text { 1. @ mh.farhanali } \\
\text { 2. @ abee1013 }\end{array}$ & $\begin{array}{l}\text { 1. Perjalanan garuda } \\
\text { pancasila dan tiga } \\
\text { lambangnya yang ditolak } \\
\text { 2. Arti gambar pada lambing } \\
\text { NKRI "garuda Pancasila" }\end{array}$ \\
\hline 5 & $\begin{array}{l}\text { Bhineka Tunggal Ika } \\
\text { sebagai semboyan } \\
\text { negara }\end{array}$ & $\begin{array}{l}\text { 1. @ zevacangtippp } \\
\text { 2. @ derrenaxelion }\end{array}$ & $\begin{array}{l}\text { 1. Bhineka tunggal ika } \\
\text { dalam keberagaman } \\
\text { agama } \\
\text { 2. Bhineka tunggal ika } \\
\text { dalam keberagaman suku } \\
\text { bangsa }\end{array}$ \\
\hline 6 & $\begin{array}{l}\text { Pancasila sebagai } \\
\text { dasar negara }\end{array}$ & $\begin{array}{l}\text { 1. \#samasamapancasila } \\
\text { 2. @ josesusanto02 } \\
\text { 3. @ fardiyandi }\end{array}$ & $\begin{array}{llr}\text { 1. Challenge } & \text { dari } \\
\text { kemendikbud } & \text { dalam } \\
\text { memperingati hari lahir }\end{array}$ \\
\hline
\end{tabular}


7. Kebudayaan daerah yang telah diterima sebagai kebudayaan nasional.
1. \#batikoutfitchallenge

2. @ satria_jogja

3. @ billymonzterga

pancasila

2. Sejarah lahirnya pancasila

3. Tiga hal positif untuk memperingati hari lahir pancasila

1. Tren yang sedang ramai di Tik Tok untuk menggunakan batik di kehidupan sehari-hari

2. Video memainkan angklung di daerah malioboro

3. Video tarian dari beberapa daerah di Indonesia

\section{PEMBAHASAN}

Berdasarkan hasil temuan data penelitian, ditemukan beberapa bentuk identitas nasional yang terepresentasikan dalam beberapa video dan hashtag yang ada di Tik Tok. Menurut Winarno (2013) bentuk-bentuk identitas nasional diantaranya dalam bentuk bahasa Indonesia sebagai bahasa nasional, Bendera Merah Putih sebagai bendera negara, Lagu Indonesia raya sebagai lagu kebangsaan, Garuda Pancasila sebagai lambang negara, Bhineka Tunggal Ika sebagai semboyan negara, Pancasila sebagai dasar negara, dan kebudayaan daerah yang telah diterima sebagai kebudayaan nasional.

1. Bahasa Indonesia sebagai Bahasa Nasional

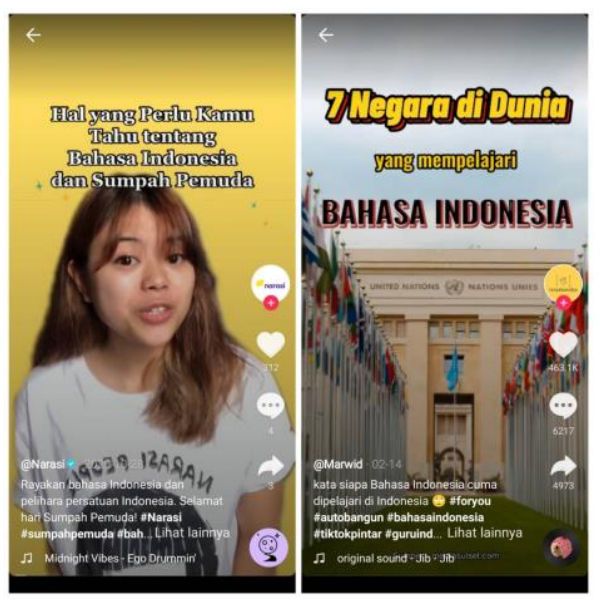

\section{Gambar 1. Contoh video Tik Tok dengan tema bahasa Indonesia}

Bahasa Indonesia adalah bahasa nasional dan persatuan di Negara Kesatuan Republik Indonesia. Menurut (Bulan, 2019) Sehubungan dengan diangkatnya bahasa Indonesia sebagai bahasa nasional, sekaligus secara otomatis sebagai identitas nasional. Pada contoh video pertama, terdapat sebuah video singkat yang berjudul "Hal yang kamu tahu tentang Bahasa Indonesia dan Sumpah pemuda" di akun Tik Tok @ narasi dan telah 
ditonton sebanyak 10.300 kali (Pada 11/03/2021). Pada video pertama dijabarkan mengenai fakta-fakta bahasa Indonesia yang lahir dalam kongres pemuda II dan sekaligus diperingati sebagai bulan bahasa. Selain itu, dalam video tersebut juga membahas isi dari sumpah pemuda khususnya poin ketiga yang membahas tetang bahasa Indonesia. Selanjutnya, untuk contoh video kedua terdapat video dengan judul "7 Negara di Dunia yang mempelajari Bahasa Indonesia” di akun Tik Tok @tanyabuwidya. Video tersebut telah ditonton sebanyak 2,8 juta kali kali (Pada 11/03/2021). Di dalam video tersebut membahas mengenai bahasa Indonesia yang dipelajari di tujuh negara berbeda di dunia. Kedua video tersebut sudah ditonton oleh puluhan ribu bahkan jutaan masyarakat. Hal ini, secara tidak langsung memberi pengetahuan dan penguatan kepada kita mengenai Identitas Nasional khususnya bahasa Indonesia. Masyarakat diharapkan bisa lebih bangga kepada bahasanya sendiri dan mempergunakannya secara baik dan benar.

2. Bendera Merah Putih sebagai Bendera Negara

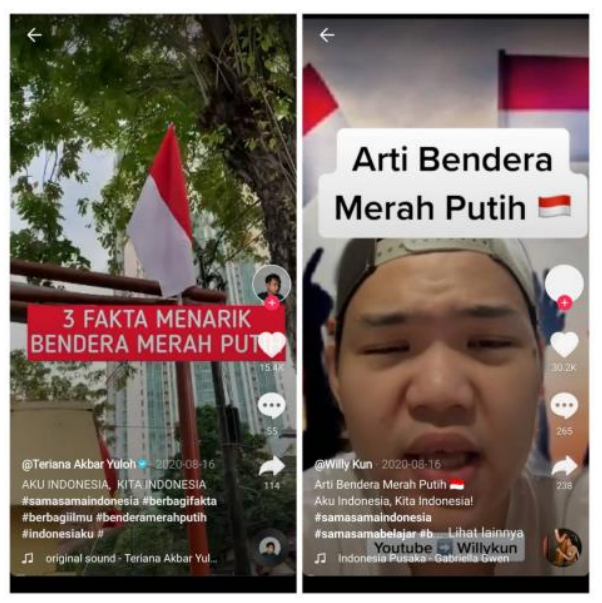

\section{Gambar 2. Contoh video Tik Tok dengan tema Bendera Merah Putih}

Bendera merah putih resmi menjadi bendera nasional kita pada tanggal 17 agustus 1945 saat kemerdekaan Republik Indonesia. Semenjak itu, bendera merah putih resmi menjadi bendera Negara yang menjadi identitas nasional bagi Indonesia. Di dalam contoh video pertama, terdapat sebuah video singkat yang berjudul "3 fakta menarik bendera merah putih" di akun Tik Tok @ teriyuloh dan telah ditonton sebanyak 280,1 ribu kali kali (Pada 11/03/2021). Pada video singkat tersebut disebutkan beberapa fakta mengenai bendera merah putih dari mulai sejarah pembuatannya sampai kapan bendera asli dipakai. Selain itu, dijelaskan juga jenis tiang apayang dipakai saat bendera tersebut pertama kali dikibarkan. Selanjutnya, ada sebuah video dari akun @ tiktokwillykun yang berjudul “Arti bendera merah putih" yang telah ditonton sebanyak 225,8 ribu kali kali (Pada 11/03/2021). Pada video tersebut menjelaskan arti dari bendera merah putih yang sesuai dengan 
kepribadian bangsa kita. Kedua video tersebut sudah ditonton ratusan ribu masyarakat. Hal ini, secara tidak langsung memberi pengetahuan dan penguatan kepada kita mengenai Identitas Nasional khususnya Bendera Merah Putih.

3. Lagu Indonesia Raya sebagai Lagu Kebangsaan

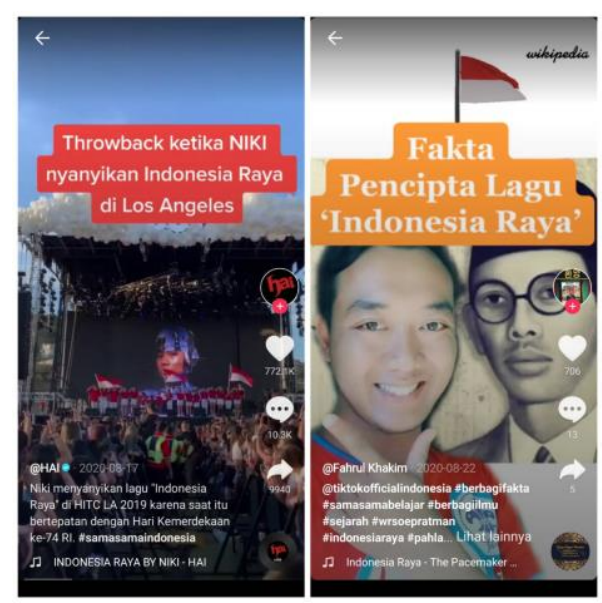

\section{Gambar 3. Contoh video Tik Tok dengan tema lagu Indonesia Raya}

Lagu Indonesia Raya menjadi salah satu bentuk identitas nasional kita yang membedakannya dengan identitas bangsa lain. Lagu Indonesia raya pertama kali diperdengarkan oleh Wage Rudolf Supratman pada tanggal 28 Oktober 1928 saat Kongres Pemuda II di Batavia. Lagu Indonesia Raya hingga kini masih terus diperdengarkan di acara resmi kenegaraan maupun upacara penaikan bendera. Contoh pertama yang akan dibahas menganai bentuk identitas nasional ini adalah sebuah video yang diposting oleh akun@hai_online dengan judul “Throwback ketika NIKI nyanyikan Indonesia Raya di Los Angeles" dengan 3,8 juta penonton (Pada 11/03/2021). Video tersebut menampilkan "NIKI" salah satu penyanyi Indonesia yang telah go internasional dan menyanyikan lagu Indonesia Raya saat acara HITC LA 2019 di Los Angeles, Amerika Seriat. Hal tersebut tentunya menjadi kebanggan kita bersama, lagu Indonesia Raya yang menjadi identitas bangsa Indonesia bisa diperdengarkan di negara lain. Selain video tersebut, contoh selanjutnya adalah sebuah video yang berjudul "Fakta lagu Indonesia Raya" yang diunggah oleh akun Tik Tok @fahrul_khakim dan telah ditonton sebanyak 14.200 kali (Pada 11/03/2021). Video tersebut menjelaskan sejarah dan fakta lagu Indonesia raya saat diciptakan oleh Wage Rudolf Supratman. Selain bisa menambah edukasi mengenai lagu Indonesia raya, video tersebut juga dapat meningkatkan rasa nasionalisme. Kedua video tersebut sudah ditonton puluhan ribu bahkan jutaan masyarakat. Hal ini, secara tidak langsung memberi pengetahuan dan penguatan kepada kita mengenai Identitas Nasional khususnya mengenai lagu kebangsaan Indonesia Raya. 
4. Garuda Pancasila sebagai Lambang Negara
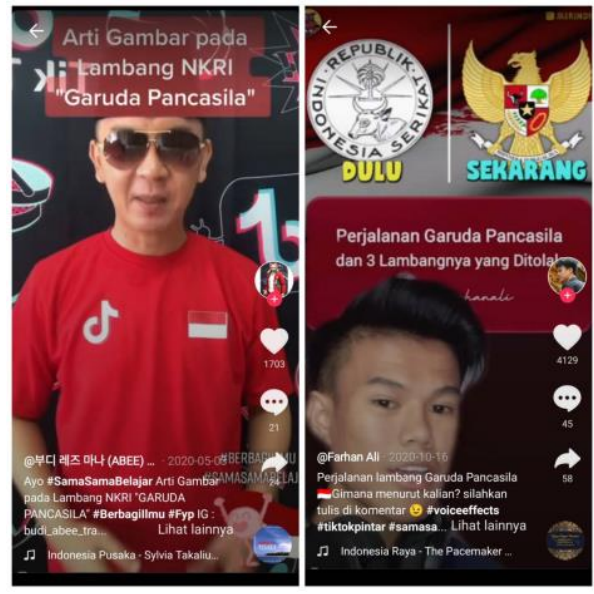

\section{Gambar 4. Contoh video Tik Tok dengan tema Garuda Pancasila}

Hampir setiap negara pasti mempunyai lambang negara yang membedakannya dengan negara lain. Garuda Pancasila merupakan salah satu bentuk identitas bangsa kita yang di dalamnya mengandung banyak filosofi cerminan bangsa Indonesia. Pada contoh video pertama, terdapat sebuah video singkat yang berjudul "Perjalanan garuda pancasila dan tiga lambangnya yang ditolak" di akun Tik Tok @mh.farhanali dan telah ditonton sebanyak 67.700 kali (Pada 11/03/2021). Di dalam video pertama dijelaskan mengenai sejarah terpilihnya garuda pancasila sebagai lambang negara Indonesia dengan proses penyeleksian yang panjang. Selanjutnya, untuk contoh video kedua yang berjudul "Arti gambar pada lambang NKRI "garuda Pancasila" di akun Tik Tok @abee1013 telah ditonton sebanyak 86.900 kali (Pada 29/04/2021). Di dalam video tersebut membahas mengenai arti dari setiap bagian lambang negara kita. Kedua video tersebut sudah ditonton oleh puluhan ribu masyarakat. Hal ini, secara tidak langsung memberi pengetahuan dan penguatan kepada kita mengenai Identitas Nasional khususnya lambang negara kita "Garuda Pancasila". Masyarakat diharapkan bisa lebih bangga kepada lambang negaranya dan mengetahui makna dan sejarah yang terjadi di dalam pembentukannya. 
5. Bhineka Tunggal Ika sebagai Semboyan Negara

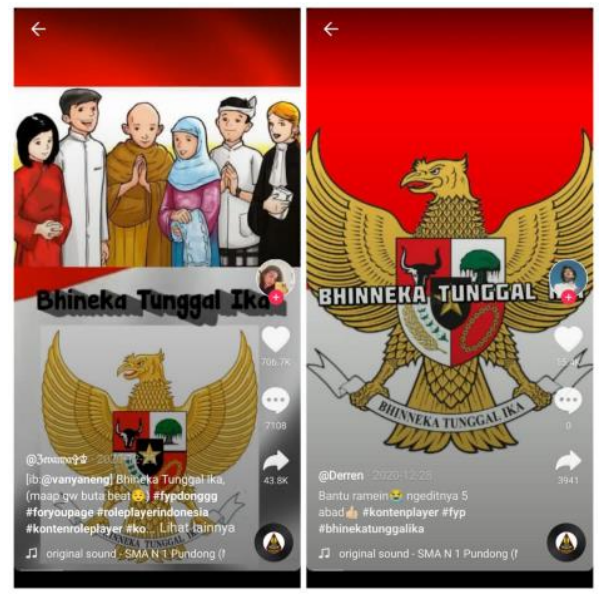

Gambar 5. Contoh video Tik Tok dengan tema Bhineka Tunggal Ika

Bhineka Tunggal Ika menjadi semboyan negara kita yang mempunyai makna berbeda-beda tetapi tetap satu jua. Pada contoh video pertama, terdapat sebuah video singkat yang isinya mengenai Bhineka tunggal ika dalam keberagaman agama di akun Tik Tok @ zevacangtippp dan telah ditonton sebanyak 2,4 juta kali (Pada 11/03/2021). Pada video singkat tersebut digambarkan 6 agama yang diakui di Indonesia dengan cirinya masing-masing. Selanjutnya, ada sebuah video dari akun @derrenaxelion yang isinya mengenai Bhineka tunggal ika dalam keberagaman pulau yang ada di indonesia dan telah ditonton sebanyak 62,3 ribu kali (Pada 11/03/2021). Di dalam video tersebut menampilkan bangunan dan wisata yang ada di masinh-masing pulau Indonesia. Kedua video tersebut menggunakan latar suara yang sama. Pada awal video terdapat voice over "Indonesia is very well known about our national motto Bhinneka Tunggal Ika" yang artinya "Indonesia sangat terkenal dengan semboyan nasionalnya Bhinneka Tunggal Ika”, lalu setelah itu latar musik dilanjutkan dengan beberapa lagu daerah dari Indonessia. Video tersebut sudah ditonton ratusan ribu masyarakat dan dari video tersebut juga dapat merepresentasian penguatan identitas nasional, khususnya dalam semboyan negara. 
6. Pancasila sebagai Dasar Negara

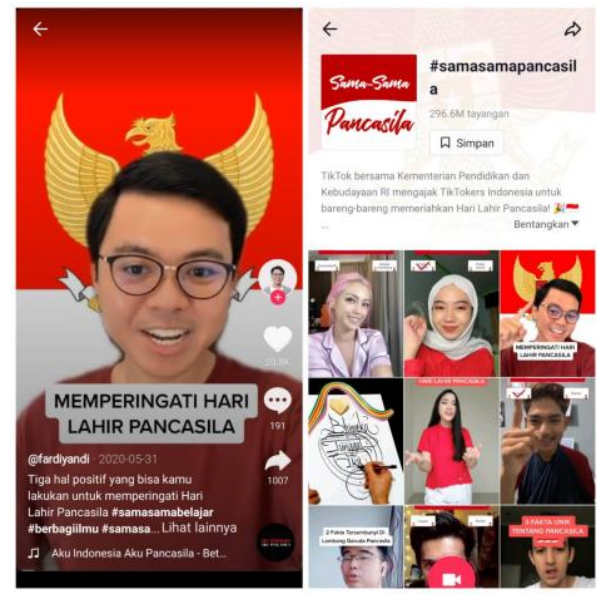

Gambar 6. Contoh video dan tagar Tik Tok dengan tema Pancasila

Pancasila merupakan dasar negara kesatuan republik Indonesia. Menurut Herdiawanto \& Hamdayama (2010) salah satu dari tiga bagian Identitas Nasional, yaitu Pancasila. Pancasila menjadi identitas fundamental sebagai falsafat bangsa, dasar negara dan ideologi negara. Sebagai ideologi negara, maka nilai-nilai Pancasila dijadikan landasan moral bagi warganegara (Supriyono, 2014). Di aplikasi Tik Tok terdapat hashtag yang digunakan masyarakat sebanyak 296.7 juta kali (Pada 11/03/2021) yaitu \#samasamapancasila. Tagar tersebut merupakan tagar yang digagas oleh Kementrian Pendidikan dan Kebudayaan dalam memperingati hari lahir Pancasila. Selanjutnya ada contoh video dari akun@josesusanto02 yang berjudul "Sejarah lahirnya pancasila" dan sudah ditonton 378 kali (Pada 11/03/2021). Di dalam video singkat tersebut dijelaskan pembentukan pancasila saat sidang BPUPKI hingga terumuskan Pancasila.

Selanjutnya yang terakhir, ada sebuah video dari akun @fardiyand yang berjudul "Tiga hal positif untuk memperingati hari lahir pancasila" dan telah ditonton sebanyak 651.4 ribu kali (Pada 11/03/2021). Di dalam video tersebut menyebutkan hal positif apa saja yang bisa dilakukan saat memperingati hari lahir pancasila, seperti saling menghargai, sikap tolong menolong, dan menonton film perjuangan untuk mengenang jasa para pahlawan. Berdasarkan hasil analisis tersebut terlihat bahwa penguatan identitas nasional khususnya mengenai dasar negara terdapat dalam konten maupun hashtag Tik Tok tersebut. 
7. Kebudayaan Daerah yang Telah Diterima Sebagai Kebudayaan Nasional

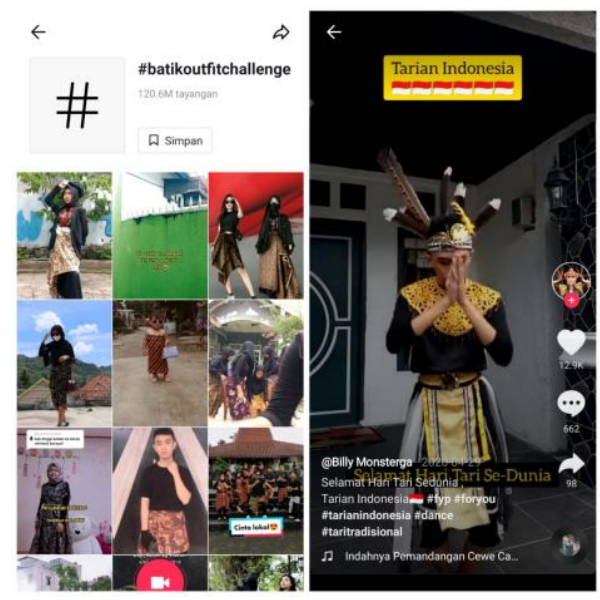

\section{Gambar 7. Contoh video dan tagar Tik Tok dengan tema Budaya Daerah}

Budaya daerah merupakan kebiasaaan atau cara hidup masyarakat yang berkembang secara turun-temurun dari generasi ke generasi. Kebudayaan daerah pun kini sudah ada yang diterima menjadi kebudayaan nasional dan menjadi identitas bangsa. Brata Ida Bagus (2016) menyebutkan bahwa bangsa Indonesia harus menyadari pentingnya mewarisi berbagai kekayaan, termasuk di dalam hal kebudayaan. Dewasa ini para pengguna aplikasi Tik Tok ramai menggunakan tagar \#batikoutfitchallenge. Challenge ini berawal dari salah satu akun Tik Tok yang menggunakan kain batik di kehidupan sehari-hari dan menjadi sebuah tren di masyarakat. Tren ini memiliki jumlah penonton sebanyak 120.6 juta (Pada 11/03/2021) dengan puluhan content creator yang turut berpartisipasi.

Selanjutnya ada sebuah video dari akun @satria_jogja yang berisi video memainkan angklung di daerah malioboro dan sudah ditonton 199.9 ribu kali (Pada 11/03/2021). Angklung sudah menjadi budaya daerah yang diakui secara nasional, bahkan pada tahun 2010, UNESCO menetapkan angkulng menjadi warisan budaya dunia asli Indonesia. Kemudian yang terakhir, ada sebuah video dari akun@billymonzterga yang berisi tarian dari beberapa daerah di Indonesia dan telah ditonton sebanyak 153.8 ribu kali. Berdasarkan hasil analisis tersebut, terlihat bahwa penguatan identitas nasional khususnya mengenai dasar Kebudayaan daerah yang telah diterima sebagai kebudayaan nasional terdapat dalam konten maupun hashtag yang diteliti.

\section{SIMPULAN}

Identitas nasional menjadi sebuah ciri dan jati diri yang membedakan suatu bangsa dengan bangsa lainnya. Bentuk identitas nasional bisa berrmacam-macam, dari mulai bahasa nasional, bendera nasional, lagu kebangsaan, dan masih banyak lagi. Di era 
pandemi seperti ini, penguatan identitas nasional mengalami berbagai macam penyesuaian dengan teknologi dan juga media yang beragam. Dari hasil analisis dan penelitian dapat disimpulkan bahwa media sosial Tik Tok berrmanfaat sebagai sarana penguatan identitas nasional di era pandemi. Penguatan identitas nasional yang ditemukan diantaranya pada bahasa Indonesia sebagai bahasa nasional, Bendera Merah Putih sebagai bendera negara, Lagu Indonesia raya sebagai lagu kebangsaan, Garuda Pancasila sebagai lambang negara, Bhineka Tunggal Ika sebagai semboyan negara, Pancasila sebagai dasar negara, dan kebudayaan daerah yang telah diterima sebagai kebudayaan nasional.

Selain itu, media sosial Tik Tok juga bisa menjadi media yang efektif untuk mengedukasi masyarakat mengenai identitas nasional bangsa Indonesia, mengingat dari hasil analisis, banyak video yang sudah ditonton ribuan bahkan jutaan kali.

\section{SARAN}

Berdasarkan hasil penelitian, Penguatan identitas nasional terdapat pada media sosial Tik Tok, seperti dalam bentuk bahasa Indonesia sebagai bahasa nasional, Bendera Merah Putih sebagai bendera negara, Lagu Indonesia raya sebagai lagu kebangsaan, Garuda Pancasila sebagai lambang negara, Bhineka Tunggal Ika sebagai semboyan negara, Pancasila sebagai dasar negara, dan kebudayaan daerah yang telah diterima sebagai kebudayaan nasional. Oleh sebab itu, aplikasi Tik Tok disarankan dipakai oleh masyarakat luas sebagai media edukasi dan penambah pengetahuan mengenai identitas nasional. Hal ini bisa menjadi solusi di era pandemi covid 19, di mana masyarakat sulit mencari media yang tepat dalam hal penguatan identitas nasional.

\section{DAFTAR PUSTAKA}

Aji, W. N. (2018). Aplikasi Tiktok Sebagai Media Pembelajaran Bahasa dan Sastra Indonesia. Prosiding Seminar Nasional Pertemuan Ilmiah Bahasa dan Sastra Indonesia, 431, 431-440.

Astawa, I. P. A. (2017). Identitas Nasional Bangsa. Universitas Udayana, 27-36.

Bayu, M., Sampurno, T., Mada, U. G., Kusumandyoko, T., Surabaya, U. N., Islam, M. A., ... Branding, V. (2020). Budaya Media Sosial, Edukasi Masyarakat, dan Pandemi COVID-19. SALAM; Jurnal Sosial \& Budaya Syar-i FSH, (April). https://doi.org/10.15408/sjsbs.v7i5.15210

Brata Ida Bagus. (2016). Kearifan BudayaLokal Perekat Identitas Bangsa. Jurnal Bakti Saraswati. Diakses Pada Hari Minggu 20 Juli 2019. Pukul 00.00 WIB, 05(01), 9-16. 
https://doi.org/10.1007/s11104-008-9614-4

Budiutomo, T. W. (2013). Pendidikan Kewarganegaraan Dalam Membentuk Karakter Bangsa. Academy of Education Journal, 4(1), 32-38. https://doi.org/10.47200/aoej.v4i1.94

Cahyono, A. S. (2016). Pengaruh Media Sosial Terhadap Perubahan Sosial Masyarakat di Indonesia. 09 No. 01, 140-157.

Herdiawanto, H., \& Hamdayama, J. (2010). Cerdas, Kritis, dan Aktif Berwarganegara: pendidikan kewarganegaraan untuk Perguruan Tinggi. Jakarta: Erlangga.

Kominfo: Blokir Tik Tok Hanya Sementara. (2018). Kominfo.

Kriyantono, R. (2007). Teknik Praktik Riset Komunikasi. Jakarta: Kencana.

PKN, T. D. (2021). Materi Identitas Nasional Konsep dan Urgensi Identitas Nasional. UPI.

Rahadian, A. (2020). Jangan Kaget, Ini Jumlah Pengguna Aktif TikTok di Dunia. CNBC Indonesia.

Supriyono. (2014). Membangun Karakter Mahasiswa Berbasis Nilai-Nilai Pancasila Sebagai Resolusi Konflik. Edutech, 13(3). https://doi.org/10.17509/edutech.v13i3.3087

Wael, A., Tiggapy, H. dkk. (2021). Representasi Pendidikan Karakter dalam Dakwah Islam di Media Sosial. Academy of Education Journal, 12, 98-113.

Winarno. (2013). Pembelajaran Pendidikan Kewarganegaraan. Jakarta: Bumi Aksara. 